\title{
GERAÇÃO E PROCESSOS FÍSICO-QUÍMICOS DE TRATAMENTO DE EFLUENTES LÍQUIDOS CONTENDO PIGMENTOS
}

\section{GENERATION AND PHYSICOCHEMICAL TREATMENT PROCESSES OF WASTEWATER CONTAINING PIGMENT}

\section{Bruna Natasha Külzer; Cristiane Oliveira Rodrigues}

\author{
Unilasalle/Canoas, Mestrado de Avaliação em Impactos Ambientais em Mineração. \\ Av. Vitor Barreto, 2288, CEP 91501970, Canoas, RS, Brasil. \\ Universidade Federal de Ciências da Saúde de Porto Alegre - UFCSPA. Rua \\ Sarmento Leite, 245, CEP 90050-170, Porto Alegre, RS, Brasil. E-mail: \\ olicristiane@gmail.com
}

\begin{abstract}
RESUMO
Em geral, as indústrias dos setores têxteis, serigrafias, lavanderias e fabricação de tintas são geradoras de efluentes líquidos, contendo altas cargas de pigmentos orgânicos ou inorgânicos de difícil remoção. Estes são um desafio para diversos sistemas de tratamento de efluentes que buscam melhorias e/ou técnicas alternativas de tratamento. Dentro deste contexto, diversas pesquisas foram conduzidas com o intuito de desenvolver processos e produtos para aumentar a eficiência de remoção de poluentes deste tipo de efluente, com a intenção de promover o atendimento da legislação vigente quanto à qualidade das águas residuárias despejadas nos corpos de água por estes setores produtivos. Assim, novos reagentes coagulantes, floculantes, adsorventes e oxidantes vêm sendo investigados em diversas formas e concentrações, visando encontrar o desenvolvimento de uma técnica, que possa se transformar em uma tecnologia economicamente viável e ambientalmente segura e atrativa. Assim, o objetivo do presente trabalho é realizar uma revisão da literatura sobre as principais características e impactos destes resíduos com ênfase para os principais processos atualmente aplicados e investigados para o tratamento de efluentes contendo pigmentos. Pretende-se visar a ampliação da discussão sobre o tema e alertar os possíveis impactos e necessidades de melhorias na legislação para a exigência da implantação de sistemas de tratamento até mesmo em micro e pequenas empresas.
\end{abstract}

Palavras-chave: Tratamento de efluentes. Remoção de pigmentos. Resíduos líquidos.

\footnotetext{
ABSTRACT

In general, the industries of textile, serigraphs, laundries and manufacture of paints sectors generate wastewater containing high loads of organic or inorganic pigments, which are difficult to remove and, so, they appear as a challenge for many wastewater treatment systems that seek improvements and/or alternative processing techniques. In this context, several studies were conducted in order to develop products and processes to increase the efficiency of uptake pollutants from effluents according to legislation to monitoring the quality of discharge of wastewater into water resources.
} 
Thus, new reagents coagulants, flocculants, adsorbents and oxidative have been investigated in some forms and concentrations, in order to find the development of a technique that can change into an economically and environmentally attractive technology. The objective of this study is to carry out a literature review reporting the main characteristics and impacts of these wastes with emphasis on the major processes currently applied and investigated to remove pigments, aiming a wide discussion about this issue and warn possible impacts and needs for improvements in legislation to implementation of treatment systems even in micro and small companies.

Keywords: Wastewater treatment. Pigment removal. Liquid wastes.

\section{INTRODUÇÃO}

$\mathrm{O}$ ato de colorir tecidos e objetos está intimamente ligado com os primórdios da humanidade, desde as pinturas rupestres passando pelos ideogramas chineses até o poder que a cor vermelha representava na Europa no século XV. Inovações tecnológicas ampliaram cada vez mais as possibilidades na indústria têxtil e serigráfica, desenvolveram-se pigmentos mais duráveis e processos eficientes e também a alteração da composição dos mesmos. O desenvolvimento da indústria química dos corantes ocorreu quando o cientista Willian Perkin, acidentalmente criou o primeiro corante sintético, na Universidade Royal de Química na Inglaterra, em 1856 (SALEM, 2010).

Atualmente, extratos vegetais são pouco utilizados dando lugar às tintas e pigmentos que possuem em sua composição substâncias que melhoram a qualidade dos produtos finais. Estes, porém, podem ser nocivos à saúde e ao meio ambiente quando gerenciados e dispostos de forma inadequada. Neste caso, as atividades de maior potencial de geração de efluentes contendo pigmentos são a indústria têxtil, de produção de tintas, corantes e pigmentos e de serigrafias. De modo geral, os despejos industriais nestas atividades são variáveis, pois dependem dos tipos de produtos finais, natureza e porte da indústria, processos, matérias primas, práticas de reuso na fonte geradora (CAVALCANTI, 2009).

Efluentes contendo pigmentos são de tratamento complexo, pois as tintas e corantes presentes nestes resíduos trazem em sua composição hidrocarbonetos aromáticos e alifáticos, proveniente dos solventes e corantes orgânicos, além de íons de metais pesados de pigmentos inorgânicos. Estes compostos permanecem nos efluentes industriais e conferem características de toxicidade aos mesmos.

Considerando o potencial de poluição de vários resíduos industriais, com o intuito de preservar os recursos hídricos, a vida aquática e a qualidade e dos corpos de água, a resolução Conselho Nacional de Meio Ambiente (CONAMA) $\mathrm{n}^{\circ}$ 430/11 (BRASIL, 2011) definiu limites máximos para diversas substâncias em efluentes lançados em águas superficiais no território brasileiro e entre elas, alguns solventes como benzeno e metais como ferro. No estado do Rio Grande do Sul a resolução do Conselho Regional de Meio Ambiente (CONSEMA) nº 128/06 (RIO GRANDE DO SUL, 2006) definiu estes parâmetros de forma específica.

Assim, visando o atendimento da legislação vigente, foram desenvolvidos processos de tratamento de efluentes que possibilitassem seu lançamento nas águas superficiais, sem risco de danos ao meio ambiente. Dentre os principais processos aplicados e investigados para o tratamento de efluentes contendo pigmentos destacam-se os processos físico-químicos de adsorção, agregação (coagulação-floculação) e oxidativos, devido a apresentarem maiores eficiências de remoção nos tratamentos.

A operação de adsorção foi considerada por Kouyoumdjiev (1992) um dos processos mais importantes utilizados na indústria e de alta eficácia, possuindo área de poros de $500 \mathrm{a} 1.500 \mathrm{~m}^{2} \mathrm{~g}^{-1}$ sendo um fenômeno onde o adsorvato (poluente) se deposita na superfície de um material 
adsorvente. Da mesma forma, Cavalcanti (2009) considerou a adsorção um meio altamente eficiente para promover a separação de compostos orgânicos e inorgânicos solubilizados, na interface de um líquido com um sólido.

Já o processo de agregação (coagulação e floculação) ocorre quando um reagente coagulante desestabiliza as cargas superficiais das partículas em suspensão no efluente, gerando agregação e, consequentemente, formação de coágulos. $\mathrm{Na}$ floculação, geralmente uma etapa posterior à coagulação, um polímero hidrossolúvel é aplicado para adsorver-se sobre os as partículas ou coágulos e formar flocos que podem ser separados por sedimentação (NUNES, 2008).

Por fim, segundo Cavalcanti (2009) os processos oxidativos utilizam oxidantes com o intuito de romper estruturas moleculares complexas de compostos orgânicos. Um dos tipos mais aplicados de processo oxidativo visa gerar o radical hidroxila (um oxidante forte), que pode ser obtido por combinações de ozônio e peróxido de hidrogênio, por exemplo. Já os processos mais convencionais realizam a oxidação pela aplicação de hipoclorito como oxidante, no entanto, na presença de substâncias orgânicas pode haver formação de compostos organo-clorados mutagênicos.

Com base nas principais características descritas e principais processos de tratamento aplicados, é possível observar que tais resíduos apresentam possibilidade de tratamento para a preservação ambiental durante as etapas de descarte. Grandes impasses, porém, ainda são observados relativos às exigências legais que são as grandes norteadoras deste processo.

Neste sentido, a Resolução CONAMA n 237 (BRASIL, 1997) em seu anexo I listou as atividades e empreendimentos sujeitos ao licenciamento ambiental, havendo entre eles a fabricação de tintas e solventes, além de tingimento, estamparia e outros acabamentos em peças do vestuário e artigos diversos de tecidos. No estado do Rio Grande do Sul a Resolução CONSEMA n 128 (RIO GRANDE DO SUL, 2006) definiu limites de lançamento de efluentes até três vezes maiores para descargas de menor vazão quanto aos parâmetros DBO, DQO e Sólidos Suspensos. Considerandose que estas variáveis na legislação aparecem como grandes problemas no que tange à questão de efluentes com pigmentos, ocorre uma quantidade de pequenas empresas com vazões relativamente baixas (serigrafias, lavanderias, tinturarias), porém com efluentes altamente tóxicos e, tendo como agravante a falta de fiscalização dos órgãos ambientais, e tudo isso evidencia uma situação concreta de poluição gerada dessas atividades.

Dentro deste contexto, o presente trabalho visa apresentar uma revisão da literatura, baseada, principalmente, em artigos científicos nacionais e internacionais, trabalhos acadêmicos (trabalhos de conclusão de curso, teses, dissertações) e livros abrangendo o estado da arte da geração e processos de tratamento de efluentes contendo pigmentos.

\section{CARACTERÍSTICAS E IMPACTOS AMBIENTAIS DOS EFLUENTES CONTENDO PIGMENTOS}

As atividades das indústrias de produção de tintas e corantes, têxtil e de serigrafias são grandes geradoras de efluentes contendo pigmentos que são resíduos complexos, cujas características podem variar de acordo com as diferentes matérias primas, condições operacionais e fases do processo produtivo.

A Secretaria do Meio Ambiente do Estado de São Paulo et al. (2003) listaram os principais produtos químicos utilizados no processo de serigrafia, destacando os solventes como acetato etílico e os desengraxantes como alcalinos-fosfatos, silicatos, carbonatos e aminas. Ainda, a emulsão fotosensível contendo álcool polivinílico, acetato polivinílico, sais diazônio, dicromatos alcalinos, corantes como ftalocianina, pigmento violeta, tiazina, plastificadores como ftalatos, fungicidas, biocidas, endurecedor como ácidos minerais, além de removedor como metaperiodato de sódio e surfactantes como hidróxido de sódio ou hipoclorito de sódio são produtos que merecem atenção 
especial devido ao alto poder de poluição dos recursos hídricos, sendo que muito destes compostos são orgânicos e por este motivo contribuíram para a apresentação de elevadas taxas de DQO na maioria dos estudos supracitados.

Um diagnóstico da poluição gerada pelas indústrias localizadas na bacia hidrográfica do Guaíba, no estado do Rio Grande do Sul, apontou demanda química de oxigênio (DQO) média de $9.900 \mathrm{mg} \mathrm{L}^{-1}$ para efluentes oriundos da fabricação de tintas e correlatos, ficando atrás apenas de efluentes provenientes do rerefino de óleos lubrificantes usados que apresentaram o valor de 14.281,3 $\mathrm{mg} \mathrm{L}^{-1}$ e efluentes de Lanifícios de $10.000 \mathrm{mg} \mathrm{L}^{-1}$, para este mesmo parâmetro (FEPAM, 1997). Yu-li et al. (2006) também citaram o potencial de poluição deste tipo de resíduo, caracterizando o efluente resultante da fabricação de corantes e demonstrando a presença de derivados de fenol, anilina e benzeno e ácidos orgânicos.

Krein (2009) caracterizou o efluente bruto da indústria de fabricação de tinta base água, encontrando DQO de 8.226, 10.864, 14.434 e 21.240 mg.L ${ }^{-1}$ em 4 amostras, sendo que as três primeiras apresentaram valores próximos à média apontada por FEPAM (1997), para este setor produtivo. Outros parâmetros como turbidez também se mostraram elevados $(61.400,130.600$, 122.600, e 119.200 NTU), assim como sólidos suspensos (6.390, 4.040, 2.600 e 8.060 mg.L ${ }^{-1}$ ), demonstrando o potencial de poluição desses resíduos e a necessidade de aplicação de tratamento, antes da disposição nos corpos receptores.

Similarmente, Lenhard et al. (2010) caracterizaram efluente bruto de lavanderia com tingimento de jeans com concentrações de demanda bioquímica de oxigênio (DBO) e demanda química de oxigênio (DQO) de 12 e $150 \mathrm{mgO}_{2} \cdot \mathrm{L}^{-1}$, respectivamente. Estes valores podem ser considerados baixos quando comparados com efluentes de outros segmentos como o têxtil, o que evidencia a variabilidade do mesmo de acordo com os processos empregados.

No que tange ao segmento das serigrafias, Meza (2010) caracterizou o efluente bruto produzido durante a lavagem de utensílios e telas em uma estamparia que utiliza o processo de quadro plano empregando estampas base água e também plastisol. Nas três amostras coletadas, o $\mathrm{pH}$ se manteve na neutralidade (entre 6 e 7), a turbidez apresentou valores entre 344 e 438 NTU, cor aparente entre 2.400 e $27.300 \mathrm{Pt} / \mathrm{Co}$, DQO entre 1.426 e $7.360,5 \mathrm{mg} . \mathrm{L}^{-1}$ e DBO de 95 a $110 \mathrm{mg} \mathrm{L}^{-1}$. Ainda nesse estudo, a autora caracterizou o efluente de outra estamparia que fez uso do processo de rolo contínuo utilizando pigmentos em $90 \%$ dos seus produtos e corantes reativos, ácidos, dispersos e acrílicos em $10 \%$ destes. Esse efluente gerado foi da lavagem das correias, cilindros, tubulações e tanques e apresentou pH entre 7,15 e 8,84, turbidez entre 620 e 763 NTU, cor aparente entre 2.540 e 9.160 Pt/Co, DQO entre 570,7 e 1.319,8 mg.L ${ }^{-1}$ e DBO de 80,5 a $130 \mathrm{mg} \mathrm{L}^{-1}$.

Assim, a descarga sem tratamento prévio de efluentes com pigmentos diretamente nas águas superficiais pode comprometer a qualidade da água dos corpos hídricos receptores, bem como a vida aquática local e por fim de toda a cadeia trófica. A elevada DQO diminui o oxigênio dissolvido disponível para peixes e outros seres aquáticos, bem como a presença de íons de metais pesados que, dependendo da concentração, pode ser letal para algumas espécies ou mesmo diminuir e impossibilitar a reprodução, além de serem recalcitrantes podendo atingir o homem no topo da cadeia trófica e causar doenças. Estas interferências alteram as relações ecológicas do meio modificando seu estado de equilíbrio.

Neste sentido, Andrade (2004) comentou a exposição do peixe zebra fish (Danio rerio) a um efluente têxtil. $\mathrm{O}$ autor constatou que a exposição causou alterações comportamentais e de ventilação em organismos adultos expostos a uma concentração igual ou superior a $26 \%$ de efluente bruto e revelou-se mais tóxica na fase de desenvolvimento embrionário.

Palácio et al. (2012) também estudou a toxicidade de um efluente têxtil (bruto e tratado) pelo processo foto-fenton artificial em Lactuca sativa (alface) e Artemia salina (microcrustáceos). Nestes estudos, o resíduo foi tratado em batelada com irradiação artificial de lâmpadas de vapor de mercúrio de $250 \mathrm{~W}$ e 0,05 g. $\mathrm{L}^{-1}$ de $\mathrm{Fe}^{2+}, 6$ g. $\mathrm{L}^{-1}$ de $\mathrm{H}_{2} \mathrm{O}_{2}$ e $\mathrm{pH}$ inicial 3, de modo que as amostras de 
efluente bruto e tratado foram, posteriormente, expostas aos bioindicadores. Estes autores mostraram que não houveram sobreviventes de Artemia salina em nenhuma diluição ou tempo de tratamento do efluente. Já Lactuca sativa foi capaz de se desenvolver parcialmente, porém apresentando diminuição da germinação e de radículas. Assim, embora o processo foto-fenton tenha se mostrado de alta eficiência na remoção de cor, DQO e turbidez, o efluente tratado continuou apresentando efeitos tóxicos nas espécies denotando a remanescência de substâncias tóxicas refratárias que não foram detectadas por estas análises, sendo este um importante fator que deve ser considerado em tais resíduos.

\section{PROCESSOS DE TRATAMENTO DE EFLUENTES COM PIGMENTOS}

Os principais processos de tratamento de efluentes contendo pigmentos são, na maioria voltado para métodos físico-químicos como a adsorção, agregação por coagulação-floculação e processos oxidativos.

Um exemplo dos processos foi estudado por Souza (2012) para a remoção do corante blue19 (azo reativo) por adsorção em partículas minerais de lama vermelha, proveniente de empresa de beneficiamento de bauxita. Esse resíduo, geralmente, contém óxidos de ferro, titânio e sílica presentes na rocha matriz e também há permanência de silicato de alumínio, sódio e com pH básico. Esse autor ativou a lama vermelha por meio de três tratamentos químicos diferentes, sendo água do mar, nitrato de cálcio e peróxido de hidrogênio além de tratamento térmico a $400{ }^{\circ} \mathrm{C}$ e $500{ }^{\circ} \mathrm{C}$. Também caracterizou quando ao $\mathrm{pH}$, condutividade elétrica, ponto de carga zero, difração de raio-X, área específica e análise granulométrica e, posteriormente, utilizou como adsorvente, investigando a cinética da reação, isotermas de adsorção e a capacidade adsorção. A maior eficiência de adsorção ocorreu no pH 4 com tempo de equilíbrio de 60 minutos, para todas as amostras. Os resultados obtidos, em geral, foram favoráveis às lamas ativadas e com queima que obtiveram percentual de adsorção maiores que $94 \%$ para concentração inicial de $500 \mathrm{mg} . \mathrm{L}^{-1}$ de corante. As lamas ativadas e sem queima obtiveram percentual de adsorção maior que $84 \%$ e a lama in natura, $73 \%$ para a mesma concentração. Houve diminuição da adsorção com o aumento da concentração de corante. A lama ativada com nitrato de cálcio a $500{ }^{\circ} \mathrm{C}$ obteve maior capacidade de adsorção com $476,19 \mathrm{mg} . \mathrm{g}^{-}$ ${ }^{1}$ e a amostra com menor capacidade $\left(172,41 \mathrm{mg} \cdot \mathrm{g}^{-1}\right)$ foi ativada com nitrato de cálcio sem queima evidenciando a lama ativada como adsorvente de baixo custo e com elevada capacidade de remoção para o corante reativo blue-19.

Calvete (2011) estudou a remoção da mistura dos corantes Vermelho de Prociona MX 3B, Preto de Celmazol B, Laranja Brilhante de Remazol, Vermelho reativo 194, Laranja Direto 4 e Azul direto 53 de efluente sintético de indústria têxtil, por adsorvente proveniente de casca de pinhão in natura, carbonizado com ácido sulfúrico, ativado química e fisicamente, seco e moído. Foram caracterizados os adsorventes quanto à granulometria, área superficial específica, volume e distribuição dos poros, microscopia eletrônica de varredura, espectroscopia vibracional na região do infravermelho, análise termogravimétrica, determinação do potencial de carga zero. Medições de absorbância no comprimento de onda máximo dos corantes foram realizados após as soluções de 20 a $200 \mathrm{~g}$ de adsorvente com $20 \mathrm{~mL}$ de solução do corante com concentrações de $5 \mathrm{mg}$. $\mathrm{L}^{-1}$ a 1.500 mg. $\mathrm{L}^{-1}$ sob agitação de 5 minutos, a 24 horas a $298 \mathrm{~K}$ com pH variando de 2 a 10 . Após avaliação estatística dos parâmetros cinéticos e das isotermas de adsorção foi concluído que estes materiais têm alto percentual de remoção de corantes, sendo que o carvão ativado química e fisicamente atingiu 99,2\% de remoção de corantes, em pH 2,5 e 98,8 \% em pH 5,0.

Dentre a gama de adsorventes alternativos atualmente estudados, Silva et al. (2013) estudaram a fibra de coco verde para a remoção de metais pesados, de efluentes provenientes da fabricação de tintas base água. Uma amostra do efluente foi coletada em indústria e caracterizada 
quanto aos metais pesados por plasma indutivamente acoplado. Já as fibras passaram por trituração com água, lavagem, secagem em estufa aerada, moagem e separação por tamisador até atingir granulometria de 25 mesh. Após ajuste de $\mathrm{pH}$ da amostra, foram adicionadas $40 \mathrm{~g}$ de fibra de côco verde em $1.800 \mathrm{~mL}$ de efluente e colocada em Jar-test a $100 \mathrm{rpm}$ por duas horas e após foi realizada filtração a vácuo. Foram analisados na fase líquida, o teor de metais presente e a fase sólida quanto a porosidade, metais pesados, $\mathrm{pH}$ e matéria orgânica. Esse estudo apontou significativa adsorção de íons de ferro e alumínio e pequeno transporte de zinco e bário para o efluente, porém não ultrapassando 0,014 e $0,174 \mathrm{mg} . \mathrm{L}^{-1}$, respectivamente, sendo inferior aos $5 \mathrm{mg} \mathrm{L}^{-1}$ definido pela resolução CONAMA n 430/11 (BRASIL, 2011) para estes parâmetros.

$\mathrm{Na}$ área dos biosorventes Kanawade e Gaikwad (2011) caracterizaram e testaram o bagaço de cana de açúcar como adsorvente em coluna fixa para remoção do corante ácido laranja II em solução aquosa. Este experimento foi realizado em uma coluna de acrílico de $100 \mathrm{~cm}$ de comprimento por $2,54 \mathrm{~cm}$ de diâmetro preenchida com cinzas de bagaço de cana de açúcar e cinzas de madeira por onde uma solução de $10 \%$ de corante foi feita passar em fluxo ascensional por diferença de potencial. As amostras foram tomadas nas alturas 15, 30 e $45 \mathrm{~cm}$ até o momento em que a concentração do corante se aproximou de $0,99 \mathrm{Pt} / \mathrm{Co}$. Os autores verificaram que a adsorção do corante é maior com um fluxo de $1 \mathrm{~L} \mathrm{~min}^{-1}, 45 \mathrm{~cm}$ de coluna, diâmetro aumentado para $3,5 \mathrm{~cm} \mathrm{e}$ com a concentração da solução de $100 \mathrm{mg} \mathrm{L}^{-1} \mathrm{em} \mathrm{pH}$ neutro e temperatura de 25 a $35^{\circ} \mathrm{C}$.

Outros biossorventes alternativos como talo de açaí e casca de cupuaçu foram investigados por Cardoso et al. (2011a) e (2011b) com o intuito de remover os corantes vermelho reativo 194, azul direto 53, preto reativo 5, laranja reativo 16 de soluções aquosas.

Nestes estudos, os talos de açaí e as cascas de cupuaçu foram lavados, secos e moídos a partículas menores que $250 \mu \mathrm{m}$. O adsorvente proveniente do talo de açaí foi acidificado com $\mathrm{HCl}$ sob agitação por $24 \mathrm{~h}$ a $70^{\circ} \mathrm{C}$ e posteriormente filtrado, lavado e seco para aumentar sua capacidade de adsorção. Estes materiais foram colocados sob agitação por 20 minutos a 24 horas com temperaturas de 298 a $323 \mathrm{~K} \mathrm{com} \mathrm{pH}$ variando de 2 a 10, massas de adsorvente entre 20 e $200 \mathrm{mg}$ e concentrações dos corantes variando de 10 à $1.200 \mathrm{mg} \mathrm{L}^{-1}$. A remoção dos corantes vermelho reativo 194 e azul direto 53 pela casca de cupuaçu atingiu cerca de $95 \%$ com pH ótimo em torno de 2 na concentração de $50 \mathrm{mg} \mathrm{L}^{-1}$ de corante em solução. Já a remoção pelo talo de açaí em p H 2 na concentração inicial do corante de $40 \mathrm{mg} \mathrm{L}^{-1}$ e tempo de contato de $12 \mathrm{~h}$ foi para os corantes preto reativo 5 foi de cerca de $90 \%$ e maior de $95 \%$ com o acidificado. A remoção laranja reativo 16 foi maior que $75 \%$ e aquela com o acidificado foi em torno de $90 \%$.

Adicionalmente, estudos de processos de agregação foram reportados por Krein (2009) que comparou a aplicação de dois tipos de polímeros naturais à base de taninos (Acquapol C1 e Tanfloc SS) nas concentrações 10\%, 15\% e 25\% (v/v) em efluentes de uma Indústria de tintas base água. O estudo foi realizado em testes de jarros com amostras coletadas após um dia de produção, onde os principais resultados mostraram que ambos os taninos obtiveram bons resultados chegando a uma redução de DQO de mais de $80 \%$, turbidez de $99 \%$, sólidos sedimentáveis de $100 \%$ de e sólidos suspensos $99 \%$.

Ainda nesta linha de pesquisa Roussy at al (2005) investigaram combinações de quitosana e tanino para a coagulação e floculação de efluente contendo a tinta violeta escuro proveniente de uma empresa de impressão em caixas de papelão. O teste dos jarros foi realizado com pH 5 e 8 sob agitação de $200 \mathrm{rpm}$ por 3 minutos para a coagulação e $40 \mathrm{rpm}$ por 15 minutos para a floculação e após 10 minutos de decantação as amostras passaram por membranas de filtração com poros de 1,2 a 1,4 $\mathrm{nm}$ e analisadas por espectrofotometria de UV-visível no comprimento de onda de $528 \mathrm{~nm}$. Neste estudo, as condições ótimas foram encontradas com pH 5 e adição de $20 \mathrm{mg} . \mathrm{L}^{-1}$ de quitosana e 70 a $100 \mathrm{mg} \mathrm{L}^{-1}$ de tanino. Este tratamento reduziu $84 \%$ da DQO e $99 \%$ da cor considerando a absorbância em $528 \mathrm{~nm}$. Os autores verificaram que em $\mathrm{pH}$ ácido diminuiu a quantidade de reagentes necessária. 
Fortino (2012) testou as concentrações $30,50,70$ e $100 \mathrm{mg} \mathrm{L}^{-1}$ de sulfato de alumínio e cloreto férrico em Jart-test como coagulantes para o tratamento de efluente proveniente de indústria têxtil. As amostras passaram por mistura rápida com $180 \mathrm{rpm}$ durante 1 minuto, mistura lenta a 30 rpm por 3 minutos e sedimentação por 15 minutos com $\mathrm{pH}$ 7. Posteriormente, foi determinada a melhor dosagem de coagulante testando concentrações de 0,2 e $0,4 \mathrm{mg} \mathrm{L}^{-1}$ de um floculante aniônico. Os resultados indicaram 50 e $70 \mathrm{mg} \mathrm{L}^{-1}$ como as melhores concentrações de coagulante, já para o floculante uma concentração intermediária foi testada $\left(0,3 \mathrm{mg} \mathrm{L}^{-1}\right)$ para $50 \mathrm{mgL}^{1}$ de cloreto férrico, mostrando ser a melhor alternativa. Neste estudo o processo de coagulação-floculação removeu a turbidez do efluente em $98 \%$.

Meza (2010) também testou o processo de coagulação-floculação, porém utilizando efluentes brutos coletados dos tanques de equalização de duas estamparias com o objetivo de otimizar o tratamento já realizado pelas empresas. Para o primeiro caso foram testadas diferentes concentrações de cal ( 0 a $450 \mathrm{mg} \mathrm{L}^{-1}$ com intervalos de $\left.50 \mathrm{mg} \mathrm{L}^{-1}\right)$ agitadas por 5 minutos a 100 rpm. Em seguida foram adicionados $500 \mathrm{mg} \mathrm{L}^{-1}$ de sulfato de alumínio com agitação de $105 \mathrm{rpm}$ por 2 minutos, sendo que a floculação ocorreu com $30 \mathrm{rpm}$ por 15 minutos.

Determinada a concentração ótima de cal o ensaio foi repetido variando a concentração de sulfato de alumínio de 300 a $800 \mathrm{mg} \mathrm{L}^{-1}$ com intervalos de $100 \mathrm{mg} \mathrm{L}^{-1}$ seguindo de mistura lenta e sedimentação. Este estudo indicou melhores resultados com pH 6,5 com $300 \mathrm{mg} \mathrm{L}^{-1}$ de cal. Para este $\mathrm{pH}$ o estudo apontou $700 \mathrm{mg} \mathrm{L}^{-1}$ de sulfato de alumínio correspondente a maior eficiência. $\mathrm{O}$ efluente tratado apresentou $15 \mathrm{Pt} / \mathrm{Co}$ de cor, 3,7 NTU de turbidez, $285 \mathrm{mg} \mathrm{L}^{-1}$ de DQO e $42 \mathrm{mg} \mathrm{L}^{-1}$ de DBO, atendendo a legislação estadual de local (Santa Catarina).

Ainda segundo Meza (2010) para o caso da outra estamparia foram comparados os desempenhos dos coagulantes sulfato de alumínio e policloreto de alumínio utilizando como auxiliar floculante o polímero aniônico FX AS6. O sulfato de Alumínio foi adicionado durante a mistura rápida (120 rpm por 2 minutos) variando de 200 a $700 \mathrm{mg} \mathrm{L}^{-1}$ sua concentração com intervalos de $100 \mathrm{mg} \mathrm{L}^{-1}$ seguindo de ajuste de $\mathrm{pH}$ para em torno de 6,5 a 7,5. Durante a mistura lenta (60 rpm por 5 minutos) foi adicionado o floculante FX AS6 em solução a 0,01\% seguido de sedimentação por 30 minutos. Os menores valores de cor (117 Pt/Co), turbidez (10,7 NTU), DQO

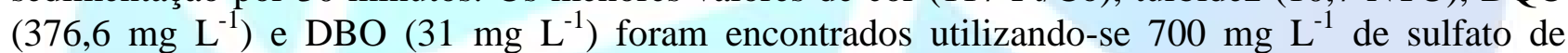
alumínio. Na sequência foi realizada análise similar a descrita anteriormente, utilizando policloreto de alumínio em concentrações de 100 a $400 \mathrm{mg} \mathrm{L}^{-1}$ com intervalos de $100 \mathrm{mg} \mathrm{L}^{-1}$. Para este coagulante a melhor dosagem encontrada foi de $400 \mathrm{mg} \mathrm{L}^{-1}$, obtendo-se um no efluente tratado com $61 \mathrm{Pt} / \mathrm{Co}$ de cor, 8,42 NTU de turbidez e $354,7 \mathrm{mg} \mathrm{L}^{-1}$ de DQO. Assim, utilizando as dosagens ótimas encontradas, a eficiência dos processos de coagulação/floculação em ambas as empresas possibilitou a remoção de mais de $97 \%$ de cor, em torno de $99 \%$ de turbidez, mais de $79 \%$ de DQO e mais de $55 \%$ de DBO.

Outro método de agregação foi testado por Wei et al. (2012) que comparou os resultados da utilização da eletrocoagulação no tratamento de efluente simulado têxtil contendo os corantes azo Preto Ácido 1, Reativo Azul Antraquinona 4, e Amarelo Eosina Xanteno com concentração de 100 $\mathrm{mg} \mathrm{L}^{-1}$ sob a ação de diferentes tipos de ânodos e agitação magnética de $740 \mathrm{rpm}$. Neste caso, foi utilizada uma chapa de ferro com $28 \mathrm{~cm}^{2}$ de área ativa como cátodo variando ânodos entre chapa de ferro, placa de aço inoxidável (ambas com $28 \mathrm{~cm}^{2}$ de área ativa) e lã de aço com $591 \mathrm{~cm}^{2}$ de área ativa. Nos testes com os cátodos de ferro e aço inoxidável a distância do ânodo foi de $1 \mathrm{~cm}$ e no experimento com a lã de aço a distância adotada foi de $1 \mathrm{~mm}$. A remoção de cor utilizando a placa de aço inoxidável foi de $81 \%, 84 \%$, e $39 \%$ para Preto ácido1, Reativo Azul Antraquinona 4, e Amarelo Eosina Xanteno, respectivamente, em 12 minutos. Já na utilização do cátodo de lã de aço houve remoção da cor em $98 \%$ após 12 minutos.

No que se refere aos processos oxidativos, Oliveira (2013) mostrou a degradação de um efluente sintético contendo diferentes concentrações do corante remazol azul brilhante (C.I. reactive 
blue-19) através de processos eletroquímicos e fotoeletroquímicos utilizando diodos emissores de luz ultravioleta (lâmpadas de LED-UV) em um reator por batelada com agitação de 200 rpm e outro tubular em fluxo com pH 6 em ambos e fotocatalisadores $\mathrm{TiO}_{2}$ e $\mathrm{RuO}_{2}$. Estes estudos mostraram uma remoção de cor de $99 \%$ após 24 horas de exposição à radiação para concentração de $50 \mathrm{mg} \mathrm{L}^{-1}$ e de $48,8 \%$ para a concentração de $100 \mathrm{mg} \mathrm{L}^{-1}$ na exposição contínua. Já no reator em fluxo com o eletrólito $\mathrm{Na}_{2} \mathrm{SO}_{4}$ a melhor eficiência de remoção de cor ocorreu em densidade de corrente de 57,3 $\mathrm{mA} \mathrm{cm} \mathrm{c}^{-2}$, tanto para o processo eletrolítico quanto para o processo fotoeletrocatalítico. Ainda, no processo eletrolítico, a eficiência foi de $65 \%$ quando realizado em $750 \mathrm{~L} \mathrm{~h}^{-1}$ durante 60 minutos e, nas mesmas condições, o uso do LED-UV aumentou apenas em $3 \%$ a eficiência da remoção de cor.

Nos estudos de Palácio et al. (2012) usando um efluente têxtil em um processo foto-fenton com lâmpadas de vapor de mercúrio de $250 \mathrm{~W}$, foram utilizadas concentrações de íons ferro $\left(\mathrm{Fe}^{2+}\right)$ de $0,05 \mathrm{~g} \mathrm{~L}^{-1}$ e de peróxido de hidrogênio $\left(\mathrm{H}_{2} \mathrm{O}_{2}\right)$ de $6 \mathrm{~g} \mathrm{~L}^{-1}$ e $\mathrm{pH}$ inicial 3,0 com 90 minutos de irradiação, sendo retiradas amostras nos tempos 5, 10, 15, 45, 60 e 90 minutos. Os melhores resultados obtidos por este autor foram aos 45 minutos de irradiação, quando DQO, cor e turbidez alcançaram reduções de 94,99 e $97 \%$, respectivamente.

Manenti et al. (2010) também investigou a fotodegradação por foto-fenton de um efluente têxtil sintético preparado com a mistura de seis corantes diferentes, peróxido de hidrogênio $\left(\mathrm{H}_{2} \mathrm{O}_{2}\right)$ e íons ferro $\left(\mathrm{Fe}^{2+}\right)$. Nestes estudos, o reator foi constituído de uma caixa de madeira, três copos Becker, três agitadores magnéticos e coletores de alíquotas, três lâmpadas de alta pressão de mercúrio de $250 \mathrm{~W}$, três ventiladores e paredes revestidas com papel alumínio para evitar perdas de irradiação e manter a temperatura interna em torno de $40^{\circ} \mathrm{C}$ durante o processo. Nesta pesquisa, nas condições de $\mathrm{pH}$ inicial 2,3 e concentrações de íons ferro de $9,3 \mathrm{mg} \mathrm{L}^{-1}$ e peróxido de hidrogênio de $65,5 \mathrm{mg} \mathrm{L}^{-1}$, os parâmetros físico-químicos e os corantes foram oxidados com apenas 5 minutos de irradiação, diferentemente dos compostos mais persistentes como os compostos aromáticos, que apresentaram resultados significantes de degradação com 60 minutos.

Nesta mesma linha de pesquisa, Lenhard et al. (2010) investigou a foto oxidação catalítica em solução de $0,01 \mathrm{~g}$ do corante comercial preto intenso e um efluente real de lavanderia com tingimento de jeans em reator de filme com catalizador $\mathrm{TiO}_{2}$ a $10 \mathrm{~g} \mathrm{~m}^{2}{ }^{2}$ com recirculação de $17 \mathrm{~L}$ $\mathrm{h}^{-1}$ e irradiação UV por lâmpadas de vapor de mercúrio de 125,250 e $15 \mathrm{~W}$ com temperatura constante de $20^{\circ} \mathrm{C}$ e sem ajuste de $\mathrm{pH}$, sendo o reator isolado para não ocorrer vazamento de luz ultravioleta. Este autor mostrou que a potência da lâmpada influenciou a remoção de cor na ausência do catalisador. Já na presença deste, uma remoção próxima a 100\% foi obtida apenas após 360 min para o efluente real os resultados mostram uma descoloração superior a $50 \%$ após 360 minutos de experimento para todas as lâmpadas avaliadas. Neste caso, com exceção da lâmpada de $125 \mathrm{~W}$, as descolorações obtidas sem catalisador foram semelhantes aos testes com catalisador, indicando que há grande absorção da radiação ultravioleta da lâmpada pelo efluente provocando a quebra das moléculas presentes no mesmo resultando na degradação por fotólise direta. $\mathrm{O}$ experimento controle sem radiação e com catalizador apresentou uma descoloração apenas próxima a $20 \%$, possivelmente devido à adsorção no catalisador.

Yassumoto (2007) investigou a degradação dos azo corantes laranja ácido 7, laranja direto 34, vermelho direto 23 e amarelo direto 86 utilizando processos de fotólise direta ( $\mathrm{UV}, \mathrm{H}_{2} \mathrm{O}_{2} / \mathrm{UV}$ e Fenton $\left(\mathrm{Fe}^{2+}\right)$ e foto-fenton $\left(\mathrm{Fe}^{2+} / \mathrm{H}_{2} \mathrm{O}_{2} / \mathrm{UV}\right)$. Soluções dos corantes foram preparadas com concentração de $1,5 \times 10^{-4} \mathrm{~mol} \mathrm{~L}^{-1}$ em água ultrapura. A degradação do corante laranja ácido nos processos fenton e foto-fenton foi de $98 \%$ e $97 \%$, respectivamente, com 45 minutos de tratamento a $30^{\circ} \mathrm{C}$ em ensaio com pH 3, concentração de $3,0 \times 10^{-2}$ mol L ${ }^{-1}$ de $\mathrm{H}_{2} \mathrm{O}_{2}$ e $5,0 \times 10^{-5} \mathrm{~mol} \mathrm{~L}^{-1}$ de $\mathrm{Fe}^{2+}$. O corante laranja direto 34 obteve maior degradação com processo fenton, cerca de $90 \%$ após 1 hora de reação a $30^{\circ} \mathrm{C}$ utilizando $7,5 \times 10^{-3}$ mol L ${ }^{-1}$ de $\mathrm{H}_{2} \mathrm{O}_{2}$ e $5,0 \times 10^{-5}$ de $\mathrm{Fe}^{2+}$ em pH 3. O corante vermelho direto 23 obteve maior degradação com processo foto-fenton, cerca de $99 \%$ utilizando $3,0 \times 10^{-2}$ de $\mathrm{H}_{2} \mathrm{O}_{2}$ e $5,010^{-4}$ de $\mathrm{Fe}^{2+}$ com 90 minutos de reação a $30^{\circ} \mathrm{C}$ e pH 3. Já o corante amarelo 
direto 86 degradou $95 \%$ após 3 horas de reação a no processo fenton contendo $7,5 \times 10^{-3} \mathrm{~mol} \mathrm{~L}^{-1}$ de $\mathrm{H}_{2} \mathrm{O}_{2}$ e $5,0 \times 10^{-4}$ de $\mathrm{Fe}^{2+}$ em pH 3 .

\section{CONCLUSÕES}

Considerando os principais geradores de efluentes contendo pigmentos citados pela literatura como indústrias de fabricação de tintas, têxteis e serigrafias e a caracterização dos efluentes realizadas por diversos autores em torno destes segmentos é possível observar como características principais destes resíduos sua elevada demanda química de oxigênio (DQO), alta taxa de sólidos em suspensão e presença de metais pesados. A presença de toxicidade nos efluentes brutos, diluídos ou tratados relatados nos estudos publicados, evidenciaram a presença de compostos letais e sub letais para os organismos teste, indicando que a escolha na combinação de processos para o tratamento deve ser avaliada para garantir a eficiência de remoção e a preservação da dos corpos hídricos e a saúde em geral. No âmbito do estado do Rio Grande do Sul, a Resolução CONSEMA 128/06 permite concentrações maiores nos parâmetros de DBO, DQO e sólidos suspensos para o lançamento de pequenas vazões de efluente. No entanto, no ramo de serigrafias é comum a existência de pequenas empresas com baixas vazões de efluente, porém com elevados valores de DQO, indicando um potencial poluidor por compostos tóxicos. Dentro deste contexto, diversas pesquisas vêm sendo realizadas com a finalidade de desenvolver novos reagentes como adsorventes, coagulantes e oxidantes e novos processos para o tratamento de efluentes contendo pigmentos. $\mathrm{Na}$ área dos adsorventes, destaque para os biossorventes, principalmente, aqueles oriundos de resíduos de outros processos produtivos que possibilitam altas taxas de remoção de poluentes evidenciando viabilidade econômica e ambiental. Na área de coagulação e floculação, os estudos mostram que os taninos são já consolidados no tratamento de diversos efluentes, com grande remoção de pigmentos, principalmente, quando combinados com produtos auxiliares de coagulação. Por fim, os processos oxidativos apresentam bons resultados em combinações com o processo fenton e a fotólise utilizando diferentes formas de radiação. Assim, diante de tais considerações, acredita-se que a revisão apresentada no presente trabalho contribui para a discussão da geração e tratamento de efluentes contendo pigmentos, reunindo dados para uma visão do cenário atual e da necessidade de tratamento destes resíduos mesmo em pequenas e médias empresas.

\section{REFERÊNCIAS}

ANDRADE, Rui Miguel Sanches Linhares de. Efeitos da exposição de peixe zebra, Daniorerio, a um efluente têxtil. 75 f. Dissertação (Mestrado em Ecologia Aplicada) Universidade do Porto, Porto, 2004.

BRASIL. Resolução n ${ }^{\circ} 237$ de 19 de dezembro de 1997. Altera a Resolução no 1/86 (revoga os art. 3o e 7o). Diário Oficial da União, n. 247, 22 dez.1997, Seção 1, p. 30841-30843. Disponível em: <http://www.mma.gov.br/port/conama/legiabre.cfm?codlegi=237>. Acesso em: 27 set. 2014.

BRASIL. Resolução ${ }^{\circ} 430$ de 13 de maio de 2011. Complementa e altera a Resolução n ${ }^{\circ}$ 357/2005. Diário Oficial da União, n. 92, 16 mai. 2011, pág. 89 Disponível em: <http://www.mma.gov.br/port/conama/legiabre.cfm?codlegi=646>. Acesso em: 27 set. 2014. 
CALVETE, Tatiana. Casca de pinhão in natura e carvão ativo: adsorventes para remoção de corantes em efluentes aquosos. 76 f. Tese (Doutorado em Química) - Universidade Federal do Rio Grande do Sul, Porto Alegre, 2011.

CARDOSO, Natalí Farias; LIMA, Eder C.; PINTO, Isis S.; AMAVISCA, Camila V.; ROYER, Betina; PINTO, Rodrigo B.; ALENCAR, Wagner S.; PEREIRA, Simone F.P. Application of cupuassu shell as biosorbent for the removal of textile dyes from aqueous solution. Journal of Environmental management. Porto Alegre, n.92, p.1237-1247, 2011a.

CARDOSO, Natalí Farias; LIMA, Eder C.; CALVETE, Tatiana; PINTO, Isis S.; AMAVISCA, Camila V.; FERNANDES, T. H. M.; PINTO, Rodrigo B.; ALENCAR, Wagner S. Application of Aqai stalks as biosorbents for the removal of the dyes reactive black 5 and reactive Orange 16 from aqueous solution. Journal of Chemical \& Engineering Data. Porto Alegre, n. 56, p.1857-1868, 2011 b.

CAVALCANTI, José Eduardo W. de A. Manual de Tratamento de Efluentes Industriais. São Paulo: Engenho, 2009.

FORTINO, Patrícia. Pós-tratamento de efluente têxtil usando coagulação/floculação combinado com processos de separação por membranas. 74 f. Dissertação (Mestrado em Engenharia Química) - Universidade Federal do Rio Grande do Sul, Porto Alegre 2012.

FEPAM - Fundação Estadual De Proteção Ambiental Henrique Luiz Roessler. Diagnóstico da poluição gerada pelas indústrias localizadas na área da bacia hidrográfica do Guaíba. Porto Alegre. 1997.

KANAWADE, Sachin M.; GAIKWAD, R.W. Removal of Dyes from Dye Effluent by Using Sugarcane bagasse Ash as an Adsorbent. International Journal of Chemical Engineering and Applications, Vol. 2, No. 3, Jun. 2011.

KOUYOUMDJIEV, Marcho Stefanov. Kinetics of adsorption from liquid phase on active carbon. Bulgária: Eindhoven University of Technology,1992.

KREIN, C. L. Utilização de taninos no tratamento de efluentes industriais de tintas. $51 \mathrm{f}$. Trabalho de Conclusão de Curso (Bacharel em Química) - Centro Universitário La Salle, Canoas, 2009.

LENHARD, D. C.; SANTOS, Alessandra Zacarias; FONTANA, Verônika Carrer; TAVARES, Célia Granhen. Foto-oxidação catalítica aplicada ao tratamento de efluentes para obtenção de água para reuso na indústria têxtil. Holos Environment, Maringá, v. 10, n. 1, p. 26- 41, 2010.

MANENTI, Diego Ricieri; GOMES, Luis Fernando Souza; BORBA, Fernando Henrique; MÓDENES, Aparecido Nivaldo; ESPINOZA-QUIÑONES, Fernando Rodolfo; PALÁCIO, Soraya Moreno. Otimização do processo foto-fenton utilizando irradiação artificial na degradação do efluente têxtil sintético. ENGEVISTA, Paraná, v. 12, n. 1. p. 22-32, jun. 2010. 
MEZA, C.M.M. Produção mais limpa e otimização do tratamento de efluentes líquidos de estamparias em Brusque e Guabiruba. 137 f. Dissertação (Mestrado em Engenharia Ambiental) - Universidade Federal de Santa Catarina, Florianópolis, 2010.

NUNES, J.A. Tratamento físico-químico de águas residuárias industriais. 5. ed., rev., ampl. e atual. Aracajú: Info Graphics, 2008.

OLIVEIRA, Clélia Aparecida da Silva. Tratamento de corante têxtil por eletrólise, fotólise e fotocatálise utilisandoutilizando LED UV. 81 f. Dissertação (Mestrado em Tecnolgia) Universidade Estadual de Campinas, Limeira, 2013.

PALÁCIO, Soraya Moreno; NOGUEIRA, Daniele Alves; MANENTI, Diego Ricieri; MÓDENES, Aparecido Nivaldo; ESPINOZA-QUIÑONES, Fernando Rodolfo; BORBA, Fernando Henrique. Estudo da Toxicidade de efluente têxtil tratado por foto-fenton artificial utilizando as espécies Lactuca Sativa e Artemia Salina. ENGEVISTA, Paraná,V. 14, n. 2. p. 127-134, ago. 2012.

RIO GRANDE DO SUL. Resolução n ${ }^{\circ} 128$ de 24 de Novembro de 2006. Disponível em: http://www.sehabs.rs.gov.br/upload/20130628115845resolucao_consema_n_128_2006 fixacao_de_padroes_de_emissao_de_efluentes_liquidos.pdf. Acesso em: 27set. 2014.

ROUSSY, Philippe Chastellan J.; VOOREN, Maurice van; GUIBAL, Eric. Treatment of inkcontaining wastewater by coagulation/flocculation using biopolymers. Water AS, França, Vol. 31 n. 3, Jul. 2005.

SALEM, Vidal. Tingimento têxtil: fibras, conceitos e tecnologias. São Paulo: Blucher Golden Tecnologia, 2010.

Secretaria de Meio Ambiente do Estado de São Paulo (SMA); Companhia de Tecnologia de Saneamento Ambiental (CETESB); Federação e Centro das Industrias do Estado de São Paulo (FIESP/CIESP); Sindicato das Indústrias Gráficas do Estado de São Paulo (SINDIGRAF). Guia técnico ambiental da indústria gráfica. São Paulo, 2003.

SILVA, Kaio Masiel Dema da; REZENDE, Luciana Cristina Soto Herek; SILVA, Cynthia Algayer da; BERGAMASCO, Rosângela; GONÇALVES, Davana Silva. Caracterização físico-química da fibra de coco verde para a adsorção de metais pesados em efluente de indústria de tintas. ENGEVISTA, V. 15, n. 1. p. 43-50, abr. 2013.

SOUZA, Kelly Cristina de. Estudo da Adsorção do corante reativo blue 19 por lama vermelha ativada por tratamento químico e térmico. $98 \mathrm{f}$. Dissertação (Mestrado em Engenharia Civil e Ambiental) - Universidade Estadual Paulista Júlio de Mesquita Filho, Bauru, 2012.

WEI, M.C; WANG, Kai-Sung; HUANG, Chin-Lin; CHIANG, Chih-Wei; CHANG, TsungJen; LEE, Shiuan-Shinn; CHANG, Shih-Hsien. Improvement of textile dye removal by electrocoagulation with low-cost steel wool cathode reactor. Chemical Engineering Journal. Taiwan, n.192, p.37- 44, 2012. 
YASSUMOTO, Liízia. Tratamento e purificação de águas contaminadas com azo corantes por processo de oxidação avançados. $80 \mathrm{f}$. Dissertação (Mestrado em Química dos Recursos Naturais) - Universidade Estadual de Londrina, Londrina, 2007.

YU-LI, Yuan ; YUE-ZHONG, Wen ; XIAO-YING, Li ; SI-ZHEN, Luo.Treatment of wastewater from dye manufacturing industry by coagulation. China: Journal of Zhejiang University, 2006. 